\title{
Character Development Creativity in Unit Blocks for Visual Spatial Intellegence Improvement of Children with Special Needs
}

\author{
Muhammad Imam Tobroni \\ Visual Communication Design \\ School of Design, Bina Nusantara University \\ Jakarta, Indonesia \\ mtobroni@binus.edu
}

\begin{abstract}
Autism is a neurodevelopmental disorder that is present from birth or early childhood. People with autism usually have impaired social interaction, difficulties in verbal and nonverbal communication, and repetitive behaviour. One of the forms of autism treatment is therapy. Vision therapy through toys that require concentration and creativity is able to treat autism as it won't limit the imagination of children with the disorder. Toys usually have their own patterns and programs that tend to limit children's creativity, imagination and visual and spatial intelligence. This can lead to children's stress and lack of confidence. A character design on unit block toys is a form of vision therapy. It develops children's visual and spatial creativity and intelligence. It also helps children to be independent and helps with their perception. Unit blocks consist of pieces of wooden blocks with different shapes and sizes that can form even bigger shapes, based on children's imagination and ability to design a space or a building. Children's visual and spatial intelligence help them visualize and notice shapes, colours, spaces, and designs of the unit blocks accurately, modify their surroundings based upon their perceptions, and recreate the aspects of their visual experiences. Playing Lego blocks will help develop the visual spatial intelligence of children with autism as it stimulates their ability to express ideas and to design a character the way they like.
\end{abstract}

Keywords—characters; unit blocks; visual spatial intelligence; autism

\section{INTRODUCTION}

Children basically love to play, to move, to sing, to dance, to draw and to do activities that can be done by themselves or together in a group. Playing is important for children's physical, social, emotional, intellectual and spiritual growth. Playing is also important for children as it helps them know their environment, learn how to interact socially, and develop their imagination and creativity. Indonesia government even made a program called Bermain sambil belajar atau belajar sekaligus bermain, which translates to "Playing while learning or learning while playing", whose goal is to raise awareness that children should have fun while learning, and vice versa, and also to help children be more spontaneous and motivated when learning something.

Playing is a learning process involving thoughts, perception, concepts, and social and physical skills. Playing as an activity naturally allows children a chance to create, explore and get to know their world [1]. Playing in general can develop a child's motoric, social and cognitive skills, and also their creativity, behaviour, language skills, and it can sharpen their senses as well. Playing is a form of a therapy for a child's physic, mental and other developmental disorders they might have. Having an active imagination stimulates children to understand themselves, to be themselves, and to think that their imagination can always grow.

Unit blocks are often seen at toy stores, with their various shapes and colours that are interesting for children. When playing with unit blocks, children are free to use their imagination and creativity to turn the unit blocks to any kind and shape they wish to make. Not only it is a good way to develop children's visual spatial intelligence, especially for the ones with autism, playing with unit blocks can also help children identify colours, shapes, sizes.

\section{ReSEARCH Methods}

Qualitative Methods - This study used qualitative methods, data collection techniques by observation, interview and documentation. The analysis used is descriptive analysis to describe how the media's role in the development of educational games early childhood cognitive abilities.

The template is used to format your paper and style the text. All margins, column widths, line spaces, and text fonts are prescribed; please do not alter them. You may note peculiarities. For example, the head margin in this template measures proportionately more than is customary. This measurement and others are deliberate, using specifications that anticipate your paper as one part of the entire proceedings, and not as an independent document. Please do not revise any of the current designations.

\section{RESULT AND ANALYSIS}

\section{A. Playing with Unit Blocks}

Children have their own way to develop and maximize their talents and intelligence potentials. Children tend to learn something that they like best and something they know they are capable of. When learning something that they like best, children are often more motivated and that they will gain new experiences and it will also stimulate their intelligence. 
Construction toys take the form of physical objects that the players can stack or build as something else, like buildings and houses for example. Construction toys are important for children as it helps develop their fine motor skills and their other muscles as well. Developed motor skills and muscles will lead to a child's good balance, movements and certain skills [3]. Children usually play with unit blocks, one type of construction toys, by stacking them and assembling them into three-dimensional models like cows, grasshoppers, houses, trees, or even planes.

Unit blocks let children's imagination and creativity grow as there is no exact rule that need to be followed. Children will keep playing with unit blocks as long as it is fun for them. Children can experiment with stacking and trying new things and even though the final result might not look like common buildings or shapes, they are at least able to visualize the shapes and images they have on their minds.

Playing is considered a fun activity as people playing do not really have to mind about the final result. Some psychologists state that playing games or playing with toys does not only affect a children's physical growth but also their mental development, imagination, visual spatial experience. Playing can also be used as a form of therapy.

Lego is construction toys made from plastic. Lego consists of colourful bricks that can be assembled and connected together to construct objects like animals, buildings, cars, weapons, and houses, all up to the players' imagination and creativity. Playing Lego blocks stimulates children's fine motor skill because children will reach for the blocks, grab and connect one block with another. It also can help develop children's creativity [4]. Furthermore, playing Lego blocks will help develop the visual spatial intelligence of children with autism as it stimulates their ability to express ideas and to design a character the way they like.

Playing with unit blocks does indeed help with children's fine motor skills and creativity but other than that, it also helps improve children emotional intelligence (EQ). Not only they stimulate children's creativity and introduce them to concepts in mathematics, art, social-emotional intelligence, unit blocks can also be an art media for children to express their talents and ideas.

There are a lot of factors that determine the growth of a child's cognitive skills and visual spatial intelligence. Playing with unit blocks lets children explore the world of ideas and choices and lets them try new ways of combining the unit blocks. Children will be able to imagine how the unit blocks will look like if they stack them into skyscrapers, hotels, and houses, or if they connect one block with another and turn them into a train.

The fact that unit blocks are easy to find and inexpensive makes them last from time to time, even when there are a lot of other toys children can play with.

Children's mind will be more active and they will be more focused when playing with unit blocks. It will also make them understand that they do not have any limit to create something out of the unit blocks, from something with the simplest form to something more complex. Children will learn the concept of mathematics like the name of geometric shapes, the difference of sizes, lengths and heights, and to socialize and communicate better. Many national and international competitions of character or model creation from unit blocks prove that playing with unit blocks also stimulates children's creativity.

\section{B. Visual Spatial Intelligence}

Children who are visually spatially gifted will find it easier to remember the objects that they have seen before. Visual spatial intelligence is the ability to observe an object in great detail. People with visual spatial intelligence are able to memorize objects that they have seen and sounds that they have heard for a long time [5].

Children with this type of intelligence will better recognize spaces and dimensions like houses, buildings, rooms, and decorations. They understand images better than words and they are able to draw an object they see or think about. Visual spatial intelligence plays an important part in a child's ability to solve a problem or to find an answer [6].

Autism is a neurodevelopmental disorder that is present from birth or early childhood. People with autism usually have impaired social interaction, difficulties in verbal and nonverbal communication, and repetitive behaviour. The difficulties that people with autism have to live with isolate them from the outside world. As autism is a complex disorder, a complete and thorough management is needed to be able to treat it.

\section{CONCLUTIONS}

These days, people have come to realize that creativity is one aspect that children need in order for their personality to develop. Creativity helps children build their personality and social skills. Playing can help stimulate children's creativity.

Children's creativity comes in different types. Some children are physically creative; they love to kick a ball, climb a tree, they sometimes even like to pick on other children. Some children are quiet and some are full of ideas. The last type of children is often expected to be creative people that can contribute to other people's lives.

For children, playing is a way to release their stress caused by limitation from their environment. Playing with toys can help children, especially the ones with autism, develop their fine motor skill, their interests and constructive ideas, and it also gives them a chance to get to know other people, interact with them, and also their environment.

Playing lets children with autism a chance to express their emotions as well, both the positive and negative ones, without putting too much burden on their shoulders. This can be a form of therapy that allows the therapists to notice what the children are good at. Besides vision therapy, parents and caregivers involvement also takes a big part in the children's communicative abilities development [7]. As parents and care givers involvement in their children's social interaction is also important, a social therapy can also be done at home by the children's family. The children's abilities will develop if the therapy is done intensely and constantly. The family will need to keep interacting with the children. 
Based on the analysis above, it can be said that a child's visual spatial intelligence can be developed in so many ways. One of the ways is to let the children play something they like that potentially help them hone their intelligence and improve their talents. For this to happen, people close to the children, family and caregivers, need to facilitate their children's needs.

\section{REFERENCES}

[1] G. Eason, B. Noble, and I.N. Sneddon, "On certain integrals of Lipschitz-Hankel type involving products of Bessel functions," Phil. Trans. Roy. Soc. London, vol. A247, pp. 529-551, April 1955. (references)

[2] J. Clerk Maxwell, A Treatise on Electricity and Magnetism, 3rd ed., vol. 2. Oxford: Clarendon, 1892, pp.68-73.
[3] I.S. Jacobs and C.P. Bean, "Fine particles, thin films and exchange anisotropy," in Magnetism, vol. III, G.T. Rado and H. Suhl, Eds. New York: Academic, 1963, pp. 271-350.

[4] K. Elissa, "Title of paper if known," unpublished.

[5] R. Nicole, "Title of paper with only first word capitalized," J. Name Stand. Abbrev., in press.

[6] Y. Yorozu, M. Hirano, K. Oka, and Y. Tagawa, "Electron spectroscopy studies on magneto-optical media and plastic substrate interface," IEEE Transl. J. Magn. Japan, vol. 2, pp. 740-741, August 1987 [Digests 9th Annual Conf. Magnetics Japan, p. 301, 1982].

[7] M. Young, The Technical Writer's Handbook. Mill Valley, CA: University Science, 1989. 